\title{
ARTICLE
}

\section{Coherence as Competence}

\author{
Maria Lasonen-Aarnio \\ University of Helsinki, Finland \\ Email: maria.lasonen@helsinki.fi
}

(Received 4 July 2021; accepted 5 July 2021; first published online 7 September 2021)

\begin{abstract}
Being incoherent is often viewed as a paradigm kind of irrationality. Numerous authors attempt to explain the distinct-seeming failure of incoherence by positing a set of requirements of structural rationality. I argue that the notion of coherence that structural requirements are meant to capture is very slippery, and that intuitive judgments - in particular, a charge of a distinct, blatant kind of irrationality - are very imperfectly correlated with respecting the canon of structural requirements. I outline an alternative strategy for explaining our patterns of normative disapproval, one appealing to feasible dispositions to conform to substantive, non-structural norms. A wide range of paradigmatic cases of incoherence, I will argue, involve manifesting problematic dispositions, dispositions that manifest across a range of cases as blatant-seeming normative failures.
\end{abstract}

Keywords: Coherence; incoherence; structural coherence; structural rationality; requirements of structural rationality; dispositional evaluations; akrasia; means-ends coherence; transmission of oughts

\section{Incoherence and structural rationality}

There is a dominant tradition in Western philosophy of viewing various incoherent states as paradigm cases of irrationality and hence, as paradigm cases of some sort of normative failure. It is irrational to believe that the world is doomed and to believe that it isn't. It is irrational to believe that I ought to make a sizeable donation to a given organization, but to fail to intend to do so. It is irrational to intend to run a marathon, believe that it is necessary to do some training beforehand, but to have no intention to train. Such incoherence doesn't depend on the credentials of the individual mental states in question, but on how one's attitudes fit together. It is a matter of purely structural features: the kinds of mental states involved (belief, intention, etc.) and relations between their contents.

Philosophers with otherwise opposing views often unite on the thought that avoiding such incoherence is necessary for theoretical and practical rationality. Within the literature on practical reasoning, there is a tradition of taking it for granted, for instance, that there is something bad about failing to intend what one believes to be a necessary means to one's ends. ${ }^{1}$ In epistemology several authors have simply taken the

\footnotetext{
${ }^{1}$ Kant relies heavily on the hypothetical imperative, taking it to be analytically true (see his Groundwork; Kant 1997). Lord (2019: 19) points out, regarding the rather vast literature on practical reason, "For the most part, the whole debate about rationality is about what best explains why you are irrational when you are incoherent in these ways".

(C) The Author(s), 2021. Published by Cambridge University Press. This is an Open Access article, distributed under the terms of the Creative Commons Attribution licence (http://creativecommons.org/licenses/by/4.0/), which permits unrestricted re-use, distribution, and reproduction in any medium, provided the original work is properly cited.
} 
irrationality of epistemic akrasia as a premise in their reasoning. ${ }^{2}$ Some claim that there is nothing to rationality beyond coherence. ${ }^{3}$ Coherence requirements have had a central place in pictures that attempt to do away with objective values and reasons. And the attempt to reduce more substantive normative requirements to the requirements of rationality is an ongoing research program with a very distinguished history. ${ }^{4}$

But what, we should ask, is the relevant kind of incoherence in the first place? It won't do to appeal to formal constraints like logical consistency, logical entailment, or the probability axioms. For instance, there doesn't appear to be anything logically inconsistent with being akratic or failing to intend what one takes to be necessary means to one's ends. ${ }^{5}$ And even if, for instance, the axioms of arithmetic together with Goldbach's conjecture were inconsistent (assuming the conjecture to be false), one might think that we can rationally believe, or have high confidence in, the conjecture. ${ }^{6}$ Nor does it help to appeal to on our ordinary talk of rationality. It is completely natural, after all, to describe a subject who ignores part of her evidence, or whose evaluation of her evidence is influenced by her desires or biases, as irrational. Similarly, a subject who chooses to undergo a painful ordeal despite lacking any positive reason to do so strikes us as irrational. But properly taking into account one's reasons or evidence does not fall within the domain of the structural kind of rationality at issue. ${ }^{7}$

Instead of first trying to characterize what unifies all cases of structural irrationality, it is common methodology for projects making coherence a cornerstone to begin by laying down requirements of structural rationality. ${ }^{8}$ It is incoherent in the relevant sense to have beliefs that are pairwise inconsistent, to fail to believe the obvious entailments of what one believes (at least in so far as one considers the question), and to be practically or epistemically akratic. It is incoherent to both intend to do A and intend to $\mathrm{B}$, when one believes that one cannot do both. It is irrational to be means-ends incoherent. ${ }^{9}$ For each pattern of incoherent states, there is a requirement of structural

\footnotetext{
${ }^{2}$ For a recent example, see e.g. Titelbaum (2015).

${ }^{3}$ Broome (2013), for instance, argues that rationality just is a matter of being coherent by satisfying various structural requirements.

${ }^{4} \mathrm{I}$ am here referring to a broadly Kantian project.

${ }^{5}$ There are programs to reduce certain coherence requirements to others. For instance, those who hold so-called cognitivist views of intention often argue that the problem with means-ends incoherence is that means-ends incoherent subjects hold contradictory beliefs, and rationality requires not holding contradictory beliefs (e.g. Harman 1976, 1986; Velleman 1989, 2000; Wallace 2001; Setiya 2007). More generally, one might think that all rational demands on intention are grounded in rational demands on belief (see Bratman 2009 for a critical discussion of such views). But even if the endpoint of a philosophical project was that all instances of the relevant kind of incoherence (including e.g. means-ends incoherence and akrasia) ultimately involve holding logically inconsistent beliefs, logic couldn't be used to delineate the starting point of the project.

${ }^{6}$ Cf. Broome (2013: 155) and Setiya (2004: 273).

${ }^{7} \mathrm{~A}$ distinction between the 'ought' of reasons and the 'ought' of rationality is often drawn in this connection (e.g. Scanlon 1998: Ch. 1; Kolodny 2005: 509-10; Broome 2013).

${ }^{8}$ E.g. Broome 2013. Note that being a requirement in this sense doesn't distribute across entailment: even if there is a requirement that one $\varphi$, and $\varphi$ 'ing entails $\psi$ 'ing, there may be no requirement to $\psi$. The intended sense of 'requirement' is close to what Broome (2013: Ch. 7) calls the source sense, as opposed to the property sense. See also Way's (2018) distinction between a weak and strong sense of 'rationally required'.

${ }^{9}$ It is plausible that degrees of confidence or credences (assuming we have them) and preferences can also be incoherent. Various constraints that don't flow from the probability axioms as such, such as Reflection, Rational Reflection, and the Principal Principle, have also been put forth as requirements of rationality; and as such, they are certainly in the spirit of coherence requirements. In what follows, I will mainly set aside requirements on credences and preferences; taking on incoherent beliefs and intentions is a big enough task. (I have argued against Rational Reflection elsewhere. See Lasonen-Aarnio 2015.)
} 
rationality prohibiting it. The total set of these requirements can then be taken to delineate the notion of coherence at issue. ${ }^{10}$

But why think a notion of coherence mapped out by some such medley of requirements constitutes an important normative category? A project that simply stipulated a notion of coherence, characterized by an assemblage of requirements, would have little appeal unless these requirements had some theoretical work to do. When arguments for structural requirements are given in the first place, these tend to appeal to their power to explain a distinct-seeming charge of irrationality. ${ }^{11}$ In what follows, one of my main aims will be to cast doubt on the putative explanatory indispensability of requirements of structural rationality. ${ }^{12}$ I will first look (\$2) at some data adduced in their favor. I will then argue $(\$ 3)$ that the proposed requirements have counterexamples, which bring out just how messy our practices of normative disapproval are, and how limited the data the discussion has focused on explaining is. The notion of coherence that structural requirements are meant to capture is very slippery, and intuitive judgments - in particular, a charge of a distinct, blatant kind of irrationality - are very imperfectly correlated with respecting the canon of structural requirements. My second aim will be to outline an alternative positive view: I argue $(\$ 4)$ that there is a better vindication of these practices, one appealing to feasible dispositions to conform to substantive, non-structural norms. Paradigmatically incoherent subjects, I will argue, manifest some normative incompetence.

\section{Some data}

Ulla intends to run an ultramarathon, and believes that it is necessary to take up running in order to do so. However, she has no intention to take up running. Surely, the thought goes, there is something wrong with Ulla. Similarly, consider Ray, who believes that global warming is a hoax, while also believing that he shouldn't believe this, for such a belief flies in the face of his evidence. Surely there is something wrong with Ray. Moreover, these failures appears different from just any old failure to take into account one's reasons. This can be seen by considering certain comparative judgments.

Consider Jay, who believes that global warming is a hoax, even though his belief is at odds with his evidence. Jay manifests a normative failure by having beliefs that run counter to his evidence in this way. But now consider again Ray, who likewise believes, against the evidence, that global warming is a hoax, but who also holds the further belief that given his evidence, he shouldn't believe that global warming is a hoax. Ray's beliefs appear to exhibit an additional kind of failure. ${ }^{13}$ Moreover, the problem with this

\footnotetext{
${ }^{10}$ It is worth noting that I won't be interested in just any deployment of theories that make coherence assumptions. For instance, economists often take an instrumental attitude to decision theory: decision theory is a useful tool for explaining and predicting behavior, irrespective of whether anything in psychological reality corresponds to preferences and subjective probabilities. The coherence assumptions regarding such states made by decision theory can be viewed as idealizations that carry no more normative implications than do idealizations in scientific theories. Second, some defenses of coherence-like norms are motivated by broader theoretical considerations, not by a concern with respecting the seeming badness of incoherence as such. One might, for instance, argue for evidentialist norms on belief and credence, while thinking that the simplest, most elegant and powerful theory of evidential support is probabilistic.

${ }^{11}$ See Way (2018) for a good discussion.

${ }^{12}$ There are many arguments in the literature against a program appealing to requirements of structural rationality, but few of these attempt to undermine their explanatory power. One major worry is that we have no good account of why such putative requirements are genuinely normative, of why we ought to be coherent (see Broome 2013: Ch. 11; see also Korsgaard 1996: Ch. 1, for the "Normativity Question"). Another often discussed charge is that such requirements lead to a problematic sort of bootstrapping (see Greenspan 1975; also for instance, Kolodny 2005; Setiya 2007; Schroeder 2009).

${ }^{13}$ Cf. Way (2018: 497-8).
} 
kind of akrasia appears to be distinct from failure to take one's evidence into account. ${ }^{14}$ The kind of criticism that seems appropriate in the case of subjects who have incoherent beliefs or intentions is distinct from the kind of criticism that seems appropriate in just any case of unresponsiveness to one's reasons or evidence, which can be complex and difficult to interpret. Incoherence seems to involve a distinct, more blatant kind of irrationality. ${ }^{15}$

Finally, the distinct charge of irrationality elicited by paradigmatically incoherent subjects appears to bring with it not just a negative evaluation, but a normative one. When considering incoherent subjects, it is at least natural to use the language of oughts: there appears to be a sense in which a means-ends incoherent subject, for instance, ought to form the relevant intention, even if her end is one that we strongly disapprove of. Clearly, this is not the sense of what one has overall reason to do; it is a more local kind of evaluation. Kolodny puts the point by saying that we need to explain the fact that "claims about rationality can function as advice, not just appraisal, that rational requirements can seem to guide responses, not simply to rate them". Our distinct, negative evaluations of incoherent subjects carry at least an apparent normativity.

It may seem that views invoking special requirements of rationality prohibiting incoherence are in a good position to account for the above data: the distinct-seeming failure in question is a matter of violating requirements of structural rationality. I will now argue that this is a poor explanation: violating structural requirements is neither necessary nor sufficient for eliciting the kind of charge of irrationality at issue. The considerations put forth below demonstrate just how malleable our judgments and evaluations are. Structural requirements require what Broome (2013) terms strict liability. But there are principled reasons to think that there is no set of such requirements one of which is always violated whenever there is a charge of a blatant kind of irrationality. This seriously undermines any attempt to defend structural requirements by appeal to their ability to explain and justify systematic patterns of normative disapproval - especially if there is a better explanation available, as I will argue there is.

\section{Structural rationality and blatant irrationality}

Above I pointed out that our ordinary uses of the word 'rational' are not restricted to cases involving a structural kind of incoherence: subjects who flout more substantive norms - for instance, by failing to correctly take into account their evidence - are often evaluated as irrational. But one might hope that within our evaluative practices, we can still distill a charge of a distinct, more blatant kind of irrationality that is structural in nature. But, as I will now argue, our intuitions and judgments are very malleable. I will first discuss two general strategies for filling in further details that make a particular instance of incoherence at least look less bad, and the kind of principled problem that arises from admitting the existence of what I will call coherence-restoring states. I then argue that some subjects who don't violate coherence requirements seem to be irrational in very much the same way as subjects who do. Once we look at a broad enough class of cases, we see that at the very least, the kind of badness that appears distinctive of incoherence comes in degree. The upshot will be that violating putative requirements of structural rationality is neither necessary nor sufficient for eliciting a charge of a distinct and blatant kind of irrationality.

\footnotetext{
${ }^{14}$ Way (2018). See also Raz (2005), who admits that incoherent subjects seem to exhibit a distinct kind of irrationality.

${ }^{15}$ Cf Way (2018: 499): "Incoherence seems like a blatant and ordinarily quite severe form of irrationality. But not all failures to respond properly to your evidence are blatant or severe cases of irrationality."
} 


\subsection{Luminosity failures and coherence-restoring states}

We have imperfect access to our own mental states. Assume that Ace believes a proposition $p$, and that he believes not- $p$. That might look like a blatant kind of irrationality. But let me fill in the details of the case. While Ace believes that he believes $p$, he doesn't believe that he believes not- $p$. In fact, he believes that he doesn't believe not- $p$ ('Why would I? That would be inconsistent with my other beliefs!' - he thinks). So, even if Ace does his best to survey the contents of his beliefs, he can find no logically inconsistent pairs: for all he believes and knows, his beliefs are perfectly consistent.

Along with many other epistemologists, I am persuaded that for just about any kind of mental state, it is possible to be in a situation in which one is in no position to know that one is in that state: few states are perfectly luminous. ${ }^{16}$ Assume that this is true of Ace. It's not just that he hasn't bothered to inspect the contents of his mind, but that he isn't even in a position to know that he believes not- $p$. Ace violates a coherence requirement prohibiting pairwise inconsistent beliefs. However, things don't look that bad from his perspective: while his beliefs are inconsistent, he cannot access the incoherence within his mind. Ace is certainly not irrational in some blatant manner, and he looks very different from the paradigmatically incoherent subjects the literature is focused on. Proponents of coherence requirements persuaded by such cases will have to weaken their preferred principles. ${ }^{17}$

It is not surprising that prominent attempts to delineate the relevant notion of coherence make luminosity assumptions. It might be tempting to think that certain combinations of states - those that are incoherent in the relevant way - pop out in a way that is difficult to miss. According to this thought, weeding out incoherence should be a simple exercise in mental house cleaning, simpler than being rational in some more demanding sense that requires doing things like taking into account one's evidence in appropriate ways. Indeed, Kolodny (2007a: 242) argues that incoherent subjects are always in a position to know that they are incoherent in a specific way: for instance, if a subject both believes a proposition $p$ and believes not- $p$, this fact is "available" to her, and she is therefore in a position to know that she either believes $p$ or believes not- $p$ without sufficient reason. This is what, Kolodny thinks, distinguishes coherent but mistaken agents from incoherent ones: coherent agents are not always in a position to know they are mistaken. But if we are sometimes in no position to know what we believe or intend, then it is simply false that incoherent subjects are always in a position to know such things.

Various attempts to bring out just why specific (putative) forms of incoherence are bad make implicit or explicit assumptions about access. For instance, Worsnip (2018) motivates a requirement prohibiting epistemic akrasia on the grounds that it is difficult for epistemically akratic subjects to make sense of themselves. But in pressing this point, he considers a case in which a subject recognizes that she is epistemically akratic, which of course requires her to have access to her own mental states - it requires her to know, or to at least truly believe, that she both believes $p$, and believes that she lacks adequate evidence to believe $p$. Being epistemically akratic, Worsnip argues, at least involves taking oneself to be believing against the evidence. But if I have no access to the fact that I believe $p$, I don't seem to be taking myself to hold a belief that goes against my evidence.

\footnotetext{
${ }^{16}$ The classic arguments for such a conclusion are in Williamson (2000: Ch. 4). It's not just epistemologists who have such worries; see e.g. Bratman (2009).

${ }^{17}$ For instance, Titelbaum (2015) defends a requirement prohibiting epistemic akrasia, but explicitly restricts the principle to cases that don't involve failures of "state luminosity", thereby excluding precisely the sort of case under consideration in which a subject is not suitably aware of her own mental states.
} 
A very common strategy in the literature on epistemic akrasia has been to point to the Moore-paradoxical nature of assertions like " $p$, but $p$ is highly unlikely on my evidence". ${ }^{18}$ But consider a subject who believes a proposition $p$, and believes that she doesn't believe it - in fact, she may have every reason to think that she doesn't believe $p$, and be in no position to know that she believes it. It would be very strange for such a subject to assert $p$. It is very difficult to think of cases in which we assert a proposition $p$, but are in no position to know that we asserted $p$. This is an important difference between believing $p$ and asserting $p$ : our beliefs are often hidden in ways that our assertions are not. This observation casts doubt on the strategy of arguing that certain mental states are defective because it would be bizarre to make the corresponding assertions.

Luminosity failures make putatively incoherent states look much better. Perhaps even more interesting are examples in which subjects hold (presumably) false beliefs about rationality, or about normative matters more generally. Di believes both a proposition $p$, and believes its negation not- $p$. However, $\mathrm{Di}$ is a dialetheist: she thinks that some contradictions are true, and that $p$ and not- $p$ is a true contradiction. Perhaps, for instance, she thinks that the proposition expressed by the Liar sentence 'This sentence is false' is both true and false. We can assume this to be a belief that Di has reached as a result of careful philosophical investigation. With this background story in place, Di's beliefs look less irrational, irrespective of whether her belief in dialetheism is true: she holds beliefs that, by the lights of her own responsibly formed belief, are rational. It is notable that John Broome, for instance, responds to such cases by weakening the condition against inconsistent beliefs:

Necessarily, if you are rational, you do not believe $p$ and believe not- $p$, unless you believe $p$ is special. (Broome 2013: 91)

The thought is that while it is incoherent to merely (1) believe $p$ and (2) believe not- $p$, it is not incoherent to (1) believe $p$, (2) believe not- $p$ and (3) believe that in one's current situation there is nothing irrational about believing $p$ and believing not- $p$. According to this line of thought, the third meta-level belief is what I will call a coherence-restoring state.

It would be ad hoc not to allow further beliefs to thus restore coherence in the case of other coherence requirements. Further, we need to consider not only subjects who believe that they are in special circumstances involving an exception to an otherwise true requirement - what about subjects who believe that a proposed requirement is not a true requirement of rationality in the first place? It might be more difficult to imagine how more radical (and perhaps wholly misguided) beliefs about what rationality requires could be justified, or how one could have reason to hold them. But note that the revisions we are considering do not impose epistemic conditions on the coherence-restoring beliefs. And this is as it should be, for such conditions would be at odds with the very idea of coherence at issue: the incoherence (or coherence) of a set of states doesn't depend on their epistemic credentials.

Moreover, I think we can have reasons (e.g. evidence) to believe false normative theories - in fact, this is inevitably the fate of a large proportion of our profession. ${ }^{19}$ As an example, consider Evie, who has been persuaded by Susanna Rinard that there are no real, specifically epistemic norms governing belief, and that practical reasons can constitute reasons for or against believing. ${ }^{20}$ Evie believes that $p$ is unlikely on her evidence, but

\footnotetext{
${ }^{18}$ See e.g. Feldman (2005), Huemer (2011), Smithies (2012), Horowitz (2014), Worsnip (2018).

${ }^{19}$ Titelbaum (2015) and Littlejohn (2018a) deny such a possibility, but they take an enkratic principle as a starting point in their argumentation.

${ }^{20}$ E.g. Rinard $(2018,2019)$.
} 
recognizes that there are ample practical reasons to believe $p$. So she is persuaded that she in fact ought to believe $p$. According to a popular characterization of epistemic akrasia, Evie is epistemically akratic - and hence, irrational. But she has principled reasons to think that despite failing to respect her evidence, she is respecting the true norms governing belief. She does not fail by her own lights in the way that paradigmatic akratic subjects do.

We are on a slippery slope. Given the concession about coherence-restoring states, one cannot formulate requirements imposing more objective conditions that demand what Broome terms strict liability. ${ }^{21}$ The problem is that every possible state that a more objective requirement deems incoherent has a coherence-restorer: for each candidate incoherent state, there are further beliefs that render one's overall mental state seemingly coherent.

The claim that believing that a state is rational can make that state rational by restoring coherence is striking. Hardly anyone thinks that meta-level beliefs to the effect that one is doing morally well can restore the morality of one's actions; or that meta-level beliefs to the effect that one is doing epistemically well (for instance, beliefs that one's belief is supported by the evidence) can restore the epistemic credentials of one's beliefs. But the problem is not just that proponents of structural rationality must accept a striking conclusion. For the concession that there are coherence-restoring states undermines the possibility of formulating any requirements to begin with - and they certainly undermine the canon of requirements put forth in the literature.

As far as I can see, the only principled way of resisting the slippery slope is by resisting the very first move: no matter what Di believes about dialetheism, it is irrational for her to hold inconsistent beliefs. But I certainly feel a strong pull to say that, at the very least, Di's believing both the Liar sentence and its negation involves a different kind of irrationality from that exhibited by paradigmatically incoherent subjects. If $\mathrm{Di}$ is irrational, her irrationality is of a rather sophisticated kind.

One response to the above arguments is to admit that any norm can be flouted in an excusable way, and the subjects considered - Ace, who lacks access to his own beliefs, and $\mathrm{Di}$, who thinks believing some contradictions is perfectly appropriate - are structurally irrational, but seem less irrational because their incoherence is excusable. ${ }^{22}$ I agree that any real norm can be excusably violated. But I want to remind the reader of the dialectic here. What reason is there to posit an array of structural requirements? These requirements, and the kind of coherence they delineate, explain our intuitive judgments and evaluations regarding a range of cases. In particular, they explain a distinct-seeming charge of a blatant kind of irrationality. But I have argued that our judgments and intuitions about cases are messy, and very imperfectly aligned with the coherence requirements we started out with. This considerably undermines any attempt to support structural requirements by appeal to intuitions or systematic patterns of a distinct kind of normative disapproval.

I have argued that violating a structural requirement is not sufficient for eliciting a judgment of a distinct, blatant-seeming normative failure. I will now argue that neither is it necessary.

\subsection{Blatant irrationality without violations of structural requirements}

Consider Al, who believes that the New York Times reported that $p$, and that there is absolutely no reason to distrust the report. However, even after considering the

\footnotetext{
${ }^{21}$ Broome (2013).

${ }^{22}$ Many thanks to Alex Worsnip for bringing up this response.
} 
question, he fails to believe $p$. This is somewhat baffling: isn't Al just irrational? He resembles an epistemically akratic subject: perhaps his irrationality is slightly less blatant, but it still appears distinct from the failure of a subject whose evidence is complex and difficult to decipher. It's puzzling that $\mathrm{Al}$ doesn't treat a reliable newspaper reported that $p$, and there is no reason to distrust the report as a reason to believe, or at least be confident in, $p$. One could try to argue that $\mathrm{Al}$ in fact violates some familiar coherence requirement. But it can't be closure, for NYT reported that $p$ and there is no reason to distrust the report doesn't logically entail $p$. Neither can Al be faulted on the grounds that he is epistemically akratic, for he may not have formed the (further) belief that $p$ is likely on his evidence, that rationality requires him to believe $p$, or that he ought to believe $p$. Al doesn't violate one of the familiar coherence requirements. Yet, he seems irrational in much the same way as paradigmatically incoherent (e.g. akratic) subjects.

Perhaps it was wrong to turn to structural requirements to explain the kind of charge of irrationality elicited by considering paradigmatically incoherent subjects. For instance, Setiya (2004: 276) argues that there is a sense of 'irrational', to be found in ordinary thought, on which irrationality is a matter of legitimate expectations: "A is irrational in doing $\phi$ only if A could be legitimately expected not to $\phi$ ". ${ }^{23}$ But cases in which subjects fail to meet legitimate expectations are not restricted to canonical cases of incoherence. For instance, at least without some elaborate background story involving false normative theories, it would seem that $\mathrm{Al}$ can be legitimately expected to form a belief based on the newspaper report. Further, what can be legitimately expected of a subject can, it would seem, shift depending on what she has access to and what she believes. It's not completely clear to me whether it is legitimate to expect subjects not to hold contradictory beliefs, but let us assume that it is. Nevertheless, such expectations are undermined if a subject has done her best to inspect the contents of her mind, and found no contradictions - though she does both believe $p$ and believe not- $p$, she is in no position whatsoever to know that she believes $p$. Or, consider a subject in the grip of a false normative theory. In so far as Di believes that some contradictions are true, including a specific one she believes, it is at least much less clear whether we can legitimately expect Di to not believe contradictions. Similarly, take Worsnip's idea that certain states are difficult to make sense of from a first-person perspective. It would seem difficult to make sense of Al's mental states, even if he doesn't violate a requirement of structural rationality.

Structural requirements offer a poor explanation of our evaluative inclinations, and of a broader class of data. In so far as structural requirements capture a distinct kind of irrationality, our evaluative practices only track it in very incomplete ways. I now turn to my positive competence-based account of the badness of incoherence. I will argue that it offers a far better explanation of our rather messy evaluative practices.

\section{The competence-based view}

A broad strategy often deployed by those who, like me, reject attempts to explain what is wrong with incoherence by appeal to structural requirements of rationality, has been to argue that necessarily, the mental states of incoherent subjects violate some substantive norm or requirement. For instance, if one believes both $p$ and not- $p$, then necessarily, one of these beliefs is not true, is not known, or is unsupported by the evidence. But this

\footnotetext{
${ }^{23}$ Setiya (2004) intends "legitimate expectation" to be understood in a normative sense; it is a matter "about whether there is anything about the agent that makes it unfair or unreasonable for anyone to hold them to the relevant expectation".
} 
is not my view: the problem with incoherence is not that one inevitably fails to believe and intend as one ought, given some more substantive norm, but that at least in paradigm cases one manifests bad dispositions, dispositions at odds with normative competence. $^{24}$

Let me demonstrate my strategy by means of an example. Assume that you are in charge of hiring a lifeguard. A good lifeguard will be disposed in certain ways: they will, for instance, take action when witnessing certain signs of aquatic distress and drowning. You have several candidates with excellent resumes, but could they recognize swimmers in distress, you wonder? Luckily, you have the tools to place them in an extremely real-seeming simulation. The reader can fill in the details as they wish, but assume that you manage to place one of the candidates, Simu, into the simulation without him noticing. You are both now standing in front of the pool, and Simu thinks that he is observing real events. Soon thereafter he has an experience as of a (simulated) swimmer making certain movements: they are upright in the water, head tilted back, with their mouth sinking below the surface and then reappearing. However, despite seemingly witnessing what is in fact a classic drowning response, Simu fails to budge.

You decide not to hire Simu. Upon being told about the virtual reality aspect of the interview, Simu responds that he only fails to act in simulations, but not in real cases. In fact, Simu draws on his philosophy background, arguing that he had no real reason to jump into the pool, given that no-one was in fact drowning. Here is a good response: you want to hire a lifeguard who has certain competences, grounded in clusters of dispositions that together dispose them to act successfully in various circumstances. Being disposed to recognize a drowning response and act appropriately is a very basic part of such competence, and failure to recognize a classic drowning response is a particularly bad kind of failure. But it is not humanly feasible to only be disposed to recognize a drowning response in real situations, but not in extremely real-seeming simulations. Almost any feasible recognitional dispositions, for instance, will be activated when encountering very real-seeming fakes, whether ones involving high-tech simulations, real-seeming hallucinations, or extremely good actors. Given facts about feasibility, whatever dispositions Simu was manifesting, these very dispositions manifest as failure to act in real situations. Even if he lacked any real reason to act, he manifested bad dispositions, ones that dispose a lifeguard to fail in a particularly bad kind of way. For this reason, his way of acting (or failing to act) in the simulation flies in the face of the kind of competence you are looking for. ${ }^{25}$ Even if Simu was having an exceptionally bad day,

\footnotetext{
${ }^{24}$ I have argued that there are cases in which a subject perfectly takes into account her reasons, but is still incoherent. See Lasonen-Aarnio (2020) and also Worsnip (2018). This is striking, as many have claimed that though being coherent doesn't entail believing or intending as one's reasons require, at least the converse is true: a subject who believes (and intends) as her reasons require is coherent (e.g. Raz 2005; Kolodny $2007 a, 2008 a, 2008 b)$. And when counterexamples to this claim are discussed, they tend to arise from cases involving optional pairs of beliefs or intentions (for instance, Broome 2013: 84-7). For a recent account somewhat different from mine that also makes use of the notion of competence, see Kauppinen (2021).

${ }^{25}$ One might argue that Simu did have reason to jump in, for it seemed to him that someone was making certain movements in the water. This ties in with my work on the New Evil Demon Problem. One tactic is to argue that even victims of systematic deceit have beliefs that do conform to substantive normative requirements, for they believe in accordance with their reasons - we might, for instance, take these reasons to consist of propositions about how things seem. Those reasons might be weaker than ours, but they are reasons nevertheless (see Lord 2019 for a defense, and Littlejohn $2018 b$ for a critical discussion). My tactic (Lasonen-Aarnio Forthcoming $a$ ) is importantly different: I argue that our inclinations to positively evaluate subjects in such "bad cases" stem from the fact that they manifest the same dispositions as subjects in good cases - we might say that they exercise epistemic competence. See also my discussion of subjective and objective reasons in Lasonen-Aarnio (Forthcoming $b$ ).
} 
and he very rarely acts as he did, the fact remains that he acted that way - and this is why he failed the test.

It is not surprising that airport security workers have been suspended for failing to detect fake bombs designed to look real, ${ }^{26}$ and that simulations are used to train pilots. It is not feasible for candidate lifeguards to have dispositions that discriminate between real-life cases of drowning and high-tech simulations, and it is not feasible for security workers to have dispositions that discriminate between real bombs and intricate decoys. ${ }^{27}$ The best ways for lifeguards and security workers to be inevitably comes with susceptibility to issue verdicts that are false positives. Whatever dispositions an airport security worker manifests when merely glancing over an image of a decoy bomb, those dispositions are bad: they manifest in other relevant situations as failure to recognize real bombs.

The kinds of successes I will be interested in below don't involve saving drowning people or detecting bombs, but in conforming to substantive, non-structural normative requirements - believing, intending, and acting as one has reason to, or simply as one ought. But the basic idea will be the same: Certain normative failures look particularly bad. For instance, it is particularly bad to fail to act (or intend to act) as one ought when one knows that one ought to act that way. Even if the paradigmatically incoherent subject in fact conforms to substantive norms, they manifest problematic dispositions, flouting at least some component of a feasible good way to be disposed. Hence, limits on how we could be disposed - limits on what basic normative competences or good dispositions will look like for beings like us - will play an essential role in the account below.

The account presented here is an application of a broader evaluative framework. ${ }^{28}$ For any act of $\varphi$ 'ing (of coming to believe, retaining a belief, forming an intention, performing an action, failing to act, etc.) and a relevant success, we can ask how good the dispositions are that one's $\varphi$ 'ing is a manifestation of. What makes a disposition good or bad is a matter of how successful its manifestations are across relevant cases in which it manifests itself. ${ }^{29}$ I will here simply assume that when things don't merely happen to us, we are manifesting some dispositions. ${ }^{30}$ That is, when an action, doxastic transition, or doxastic state can be in some sense attributed to an agent, it is the manifestation of some of her dispositions. ${ }^{31}$ These dispositions can be rather local and circumscribed - for instance, they may be dispositions that one only acquires when in certain company. Hence, being positively evaluable does not require having anything like a full-fledged virtue or competence, and being negatively evaluable is compatible with being virtuous or competent, for one might on this occasion manifest bad dispositions.

\footnotetext{
${ }^{26}$ https://www.bbc.com/news/uk-england-manchester-19856533. Thanks to Jaakko Hirvelä for pointing this out to me.

${ }^{27}$ For more on this notion of discrimination, see Lasonen-Aarnio (2021).

${ }^{28} \mathrm{I}$ spell out and defend the framework in a book under progress. For some applications, see Lasonen-Aarnio (2010, 2020, 2021, Forthcoming $a, b$ ).

${ }^{29}$ For more details, see Lasonen-Aarnio (2021, Forthcoming $a, b$ ).

${ }^{30}$ This should not be conflated with the false claim that actions attributable to an agent always arise out of habit, or that we only ever do things we are generally disposed to do (see also Lasonen-Aarnio 2021).

${ }^{31}$ I will here largely set aside cases in which a subject is incoherent, but this is not a manifestation of any of her (even local or circumscribed) dispositions. This includes, for instance, cases in which a subject's brain is stimulated in such a way that she holds inconsistent beliefs. Note, however, that my account can draw a distinction akin to that between doxastic and propositional justification: we can both ask how good the dispositions in fact manifested are, and how normative competence or good dispositions would manifest in one's current situation. For more on this distinction see Lasonen-Aarnio (Forthcoming $b$ ).
} 
As many authors have pointed out, the kind of normative disapproval elicited by cases of incoherence is local, and distinct from evaluations regarding what an agent overall ought to do. Ulla intends to run an ultramarathon in November, and it is now March. As it happens, this is not something she ought to do: Ulla has bad knees, tends to get dehydrated, hates running, finds ultrarunners boring, and has very little time. On the one hand, Ulla ought not to take up running; she should think of goals that better contribute to her wellbeing. On the other hand, much of the literature on instrumental reason aims to make sense of the verdict that Ulla ought to intend to go on runs - after all, it is necessary to do that, given her intention to run the ultramarathon. The challenge is to be able to make sense of and explain both verdicts. $^{32}$

To capture the local kind of badness that paradigm cases of incoherence seem to involve, it will be helpful to bring in talk of competences. Normative competences, I will assume, are grounded in (and perhaps identical to) clusters of dispositions that together dispose one to succeed - to do, act, and intend as one ought - across a range of different situations. The idea will be that paradigmatically incoherent subjects flout some component of normative competence, believing or intending in ways that are incompatible with manifesting some of the component dispositions. Whatever dispositions they do manifest are bad, given some (component of) normative success: across relevant counterfactual cases in which these dispositions manifest themselves, one fails in a particularly bad-looking way. The fact that these normative failures strike us as particularly bad explains the distinct-seeming failure of paradigmatically incoherent subjects. Blatantness comes in degrees, and any cutoff point may be arbitrary. And even more importantly, one of the lessons of $\$ 3$ was that our evaluative inclinations and practices are messy. As long as it is true that some normative failures strike us as worse than others, and as long as I can explain the seeming badness of paradigm cases of incoherence by appeal to dispositions to fail in these particularly bad-seeming ways, it doesn't matter if, rather than tracking joints in normative reality, our judgments of blatantness are reflections of something like our expectations as evaluators. If incoherence turns out to be a messy family resemblance concept, that is a problem for views in which it figures as a foundational cornerstone, but more or less what we should expect given my view.

For reasons of space, I cannot exhaustively treat all of the structural requirements ever proposed in the literature. I will focus instead on the most central and often discussed ones, with the bulk of the discussion focusing on practical akrasia and means-ends incoherence. I will also make some brief remarks about inconsistent beliefs and closure incoherence.

\subsection{Akrasia $^{33}$}

Here is a rather standard understanding of what akrasia involves: to be akratic is either to believe that one (overall) ought to do A, while failing to intend to do A, or to believe that one ought not to do A, while nevertheless intending to do A. It is a kind of clash between one's intentions and one's normative beliefs. Below I discuss problems with formulating a requirement of means-ends incoherence that also affects this characterization of akrasia, but for now I will bracket these problems.

My positive account of the distinct-seeming badness of paradigmatically akratic agents appeals to the distinctive-seeming badness of certain normative failures to intend

\footnotetext{
${ }^{32}$ See for instance Setiya (2007: 650) on the puzzle: "How can it be true, at once, that I should take the necessary means to an end - and that I should not?"

${ }^{33}$ This section draws heavily on Lasonen-Aarnio (2020), in which I focus on epistemic akrasia.
} 
to do what one ought to do. I want to abstract away from questions of what the substantive, non-structural norms on belief, intention, and action are (e.g. should we believe what is true, what is known, or what is likely on our evidence?) For this reason I will deploy the ideology of reasons. My use of this ideology should not be interpreted as indicative of a commitment to any sort of "reasons first" program: I don't assume, for instance, that all normativity can be reduced to reasons. For all I say, moreover, the relevant reasons consist of one's evidence, which in turn is the totality of propositions one knows. In the end, my account could be stated without any talk of reasons: instead of saying that it seems blatantly bad to fail to intend to do A when I ought to do $A$ is among one's reasons, I could instead observe that it seems blatantly bad to fail to intend to do A when one knows I ought to do A.

I will make the following assumptions about reasons. First, not all reasons are mental states: at least some reasons are propositional. ${ }^{34}$ (Note that a non-mentalist view of normative reasons is the standard view in meta-ethics. ${ }^{35}$ ) Second, $p$ cannot be a normative reason for belief or action if $p$ is false: falsehoods may serve as merely apparent reasons, but not as genuine reasons. ${ }^{36}$ Third, I shall assume that there is a distinction between normative reasons and the normative reasons a subject has. ${ }^{37}$ In order for a true proposition $p$ to be among the reasons I have, I must bear some appropriate epistemic relation to $p$. I will assume that the relation entails believing $p$. For instance, that the number 6 tram is not currently operating might be a reason to take the metro instead, but if I bear no epistemic relation to the proposition that the number 6 tram is not operating (unless I, minimally, believe it), I may have no reason to take the metro. I find it plausible that $p$ is a possessed normative reason just in case $p$ is part of one's evidence, and that $p$ is part of one's evidence just in case it is known. However, nothing I say below will assume this.

There are all sorts of reasons to believe and act, but I now want to focus on a special class. Consider the propositions I ought to do A, or I ought not to do B, for some actions $A$ and $B$. In so far as I have any grasp on the notion of a reason, I find it difficult to deny that the first is (when true) a reason to do A, and that the second is (when true) a reason not to do B. If anything does, the first certainly counts in favor of doing A, and the second counts against doing $\mathrm{B} !^{38}$ In fact, the force of these reasons is maximal, for they are conclusive: there couldn't be other reasons that outweigh them in the overall balance of reasons. My situation might change, and I may acquire new reasons against doing A the result of which is that I no longer ought to do A, but were this to happen, I ought to do A would no longer be true, and hence, not a genuine reason. But there is also another important respect in which these reasons are special, for they as it were wear their force on their sleeves. It is sometimes hard to figure out what I overall ought to do, even when it is clear what the relevant considerations are - for instance, there may be a multitude of considerations pulling in different directions - but it is not that hard to figure out that I ought not to do B doesn't count in favor of doing B. The force of such reasons - what they point to - is conspicuous in a way that the

\footnotetext{
${ }^{34}$ In so far as there is a distinction to be drawn between facts and true propositions, some non-mentalists might think that it is facts, not propositions, that are candidates for normative reasons. In what follows, I will speak as though propositions can be epistemic reasons for belief, though the structure of the account offered does not essentially rely on taking propositions, as opposed to facts, to be such reasons.

${ }^{35}$ See Sylvan (2016) for a good discussion.

${ }^{36} \mathrm{For}$ an overview of the debate, and a defense of the idea that all normative reasons are facts or true propositions, see Littlejohn (2018b).

${ }^{37}$ For the terminology, see Sylvan (2016).

${ }^{38}$ See Johnson King (2019) for an excellent criticism for so-called buck-passing accounts of moral rightness.
} 
force of many of our reasons is not. ${ }^{39}$ At least without some elaborate background story, failing to appropriately take such reasons into account appears blatantly vicious: in the absence of additional information, we expect agents to be appropriately responsive to them.

Consider Sai, a subject in a difficult and complicated situation who must balance the welfare of various members of his family, and come to a decision about how to use limited financial resources. In fact, Sai ought to use his savings to fund his children's education. Nevertheless, he just cannot figure out what he ought to do - quite understandably, given the complex nature of his situation. Luckily Sai can consult an omniscient oracle. The oracle tells him that he ought to invest in his children's education, and Sai believes what he is told, thereby coming to know what he ought to do. If he still forms no intention to invest in his children's education, it is considerably more difficult to make sense of him: it will certainly no longer do to point to the complex and opaque nature of his situation. Sai's failure at this point looks distinct and more blatant than his initial failure, for it is no longer unclear to him what he ought to do.

My general suggestion will be that the seeming badness of akrasia can be explained in terms of the badness of failing to take into account conspicuous reasons, which, at least other things being equal, constitutes a blatant-seeming normative failure. More precisely, the badness of akrasia is a matter of manifesting dispositions that indiscriminately manifest as failure to take into account seeming conspicuous reasons, whether or not those seeming reasons are real. ${ }^{40}$ In this respect, the akratic subject is like the candidate lifeguard who fails to respond in a simulation of someone drowning, or the airport security worker who fails to respond to an image of a real-looking decoy bomb.

My account relies on an assumption about feasibility. The core assumption will be that it is not feasible to have dispositions that discriminate between cases in which one has a genuine reason, and cases in which one has a mere belief. As a special case, it is not feasible to have dispositions that discriminate between cases in which one possesses the real reason I ought to do A (or I ought not to do B), and cases in which one merely believes this. Beliefs serve as the inputs of certain inferences leading to other beliefs - and more generally, trigger doxastic revisions - and interact with motivational states like desires and intentions to produce action. This much is almost uncontroversial. But in basing further beliefs via inference on a belief in $p$, and using this belief as a basis for action, one treats $p$ as a reason. Here is what I find to be a very appealing, albeit rough, characterization, of the functional profile of belief: believing $p$ looks, from the inside, like possessing the genuine reason that $p .{ }^{41}$ That is, belief

\footnotetext{
${ }^{39} \mathrm{I}$ am not claiming that when I ought to do $\mathrm{A}$ is a reason (and hence, is true), it is conspicuous that it is a reason (and hence, that it is true). The conspicuousness has to do with what the reason, if true, supports doing.

${ }^{40}$ Note that it is no part of my view that in general, having doxastic states that are appropriate given one's reasons or evidence requires holding higher-order beliefs about what it is rational (irrational) to believe, or about what is made likely (unlikely) by one's evidence. (Hence, I disagree with e.g. Kolodny (2008a: 457), who argues that a disposition to believe as reason requires has two constitutive parts: a disposition to form true beliefs about what reason requires, and a disposition to form or adjust doxastic attitudes in response to one's beliefs about what reason requires.) I suspect that the vast majority of the time we respond directly to our reasons or evidence, without forming such higher-order beliefs. This is perfectly compatible with the existence of such conspicuous reasons, and the thought that failing to appropriately respond to them, when one has them, appears blatantly bad.

${ }^{41}$ Cf. e.g. Ross and Schroeder (2014: 270), who argue that "believing a proposition essentially involves an automatic disposition to treat it as true in reasoning". Note that I am not proposing that believing $p$ is treating $p$ as one ought to treat $p$, were $p$ a genuine normative reason. In the intended sense of treating, even a subject who infers $q$ from $p$ and if $p, q$ by affirming the consequent can be treating $p$ as a reason.
} 
plays the same local role as the epistemic state required for possessing a genuine normative reason - for instance, if possessing $p$ as a reason requires knowing $p$, then belief plays the same local role as the state of knowing. ${ }^{42}$

A subject treats the contents of her own beliefs in the same way as she treats genuine reasons. It follows from this that competent subjects respond to mere beliefs in ways that are appropriate when possessing genuine reasons. If this is right, then exercising basic competence with reasons like I ought to do A will involve forming an intention to do A (if one doesn't already have it) based on a mere belief that one ought to A, just as exercising one's competence qua airport security worker will involve taking action when encountering a mere real-looking decoy bomb. Similarly, exercising a competence to respond appropriately to I ought not to do $B$ will involve giving up one's intention to do B (if one has such an intention) in response to one's belief that one ought not to do B.

Here, then, is my positive account of why paradigmatic cases of akrasia seem bad, and of what this badness involves. Consider the akratic subject who believes that she ought to do A, but who fails to intend to do A. There are two kinds of cases to consider. First, I ought to do A may be among the subject's reasons, which entails that she ought in fact to do A. If she fails to intend to do A, then she fails to appropriately respond to a real conspicuous reason she has - which is surely a very bad kind of normative failure. More interesting and trickier are cases in which, though she believes I ought to do A, this proposition is not among her reasons. Assume that it is false and hence, cannot be a real reason. ${ }^{43}$ Since it is false that she ought to do A, she is not flouting substantive normative requirements by failing to intend to do A. But now consider the disposition she manifests by being thus unresponsive to the contents of her belief that she ought to do A. She manifests at least a local disposition to fail to intend to do something that she believes she ought to do. How good is this disposition - does it fare across counterfactual cases in which it manifests itself? Well, given the above point about feasibility, it doesn't fare well across those counterfactual cases in which the contents of the subject's beliefs in fact constitute genuine reasons: in those cases disregarding the contents of beliefs such as I ought to do A constitutes failure to take into account a real reason. And such a normative failure seems particularly bad.

It is important to note that a subject may simultaneously be manifesting some good and some bad dispositions. In fact, she may even be exercising some part of competence, while flouting others. Assume that Dr Akra is epistemically akratic: she believes that she ought to do A, but she fails to intend to do A. However, Akra's belief that she ought to do A is false, and may even be based on no good reasons or evidence. In believing that she ought to do A, Akra fails to believe as she ought. But this does not wash out the failure of being akratic. True, Akra may act and intend exactly as she ought - from this perspective, she may even be better off not taking heed of her false normative belief. But recall that the kinds of evaluations that go together with imputing some form of incoherence are local: we might criticize a subject for failing to intend to do what she believes she ought to do, while recognizing that overall this isn't such a bad thing, given how skewed her beliefs about what she should do are. ${ }^{44}$ On the account I have sketched, the badness of being akratic involves manifesting some problematic dispositions, dispositions that manifest across a range of cases as a certain kind of blatantseeming normative failure, and that fly in the face of some component of normative

\footnotetext{
${ }^{42}$ Cf Williamson (2017).

${ }^{43}$ On many views, $p$ could fail to be a possessed normative reason for some other reason: even if $p$ is both believed and true, one may fail to bear the required epistemic relation (such as knowledge) to $p$.

${ }^{44}$ E.g. Setiya (2007).
} 
competence. Even if, all things considered, a subject in fact does better by failing to intend to do A while believing that she ought to do A, she is still manifesting a bad disposition. $^{45}$

Various accounts of conspicuousness are compatible with my proposed explanation. An account of conspicuousness might appeal to special epistemic features of the relevant reasons: perhaps we have a special kind of epistemic access to what these reasons are reasons for or against, where the access might be a priori, or conceptual/analytic, flowing from an understanding of the relevant concepts, etc. Or, an account of conspicuousness might appeal to our expectations as evaluators: absent background information, conspicuous reasons are reasons that we expect any minimally competent subject to be able to appropriately take into account. ${ }^{46}$ Relatedly, it may be that the more conspicuous a reason is, the more of an explanation we need in order to rationalize, or make sense of, a subject who fails to take into account the reason in question. Whatever conspicuousness amounts to, my account ties together the conspicuousness of a reason with our inclinations qua evaluators: other things being equal, subjects who fail to take into account conspicuous reasons fail in a blatantly bad-seeming way. For all I say, the conspicuousness of a reason just is a matter of how we tend to evaluate failures to take it into account.

Whatever the correct account of conspicuousness is, whether or not $R$ is a conspicuous reason to $\varphi$ can depend both on matters of access to our own mental states, as well as on possible normative beliefs. For instance, $p$ is unlikely on my evidence is a conspicuous reason to not believe $p \cdot{ }^{47}$ However, it may not be conspicuous to a subject in the grip of a false theory who thinks that what she ought to believe is not a matter of what her evidence supports. As an example, consider our subject who has been persuaded by Susanna Rinard that there are no real, specifically epistemic norms governing belief, and that practical reasons can constitute reasons for or against believing. She believes that $p$ is unlikely on her evidence, but recognizes that there are ample practical reasons to believe $p$. So she is persuaded that she in fact ought to believe $p$. Even if Rinard is wrong and $p$ is unlikely on my evidence is a reason not to believe $p$, the failure of such a subject is no longer blatant. For instance, we may no longer expect her to correctly take the reason into account, and it is much easier to make sense of why she doesn't believe $p$, despite believing that it is likely on her evidence. Even if she fails normatively, her failure is now of a more subtle, less blatant kind.

I have argued that at least paradigmatically akratic subjects manifest a problematic disposition: a disposition to be unresponsive to the contents of certain beliefs, a disposition that fails to discriminate between cases in which she has a merely apparent reason and cases in which she has a genuine conspicuous reason. The account I have proposed locates akrasia in a larger class of failures that involve manifesting problematic dispositions. The sense that akrasia is a distinct kind of failure is explained by the special nature of the kinds of reasons discussed above - in particular, their conspicuousness. The distinctness of the failure to appreciate the force of such reasons is one of degree, not kind. But this is as it should be, given the arguments in the first half of this paper.

\footnotetext{
${ }^{45}$ See my discussion of dilemmas in Lasonen-Aarnio (Forthcoming $b$ ).

${ }^{46} \mathrm{Cf}$. Setiya's (2004) notion of a legitimate expectation. Setiya discusses legitimate expectations that an agent will conform to requirements of practical rationality. On my account, of course, such requirements play little role. Rather, what is at issue is legitimate expectations that one respond, and be disposed to respond, to conspicuous reasons.

${ }^{47}$ Cf. Lasonen-Aarnio (2020).
} 


\subsection{Inconsistent beliefs and closure incoherence}

The competence-based account is straightforward to apply to various other putative cases of incoherence.

Consider, for instance, a subject who both believes a proposition $p$, and believes its negation, not- $p$. $p$ is a conclusive and conspicuous reason to not believe not- $p$, and not- $p$ is a conclusive and conspicuous reason to not believe $p$. If I possess the reason it's raining, then I have a conspicuous reason not to believe that it is not raining; if I possess the reason it's not raining, then I have a conspicuous reason to not believe that it is raining. Failure to appropriately take into account such reasons appears blatantly bad, in a way that failure to take into account complex meteorological data supporting rain does not.

Consider also subjects who are closure incoherent. I will assume that it is not incoherent in the intended sense to fail to believe just any entailment of what one believes: first, some entailments are not at all obvious (for instance, complex mathematical theorems) and second, cluttering one's mind with all sorts of irrelevant beliefs might be a positively bad thing to do. But it certainly seems bad to fail to believe a proposition $q$ if one believes $p$, the entailment between $p$ and $q$ is obvious enough, and the question about whether $q$ is salient. Now, when the entailment between $p$ and $q$ is obvious enough, $p$ is a conspicuous reason to believe $q$. Hence, the problem with closure incoherent subjects is that they fail to exercise a competence to respond to conspicuous reasons. Assuming that believing all of the obvious entailments of one's beliefs is not a desideratum, the competence in question involves engaging in such conspicuous pieces of reasoning only when a given question arises to salience - for instance, when a she cares about whether a given proposition is true.

I have argued that the seeming badness of many paradigm cases of a blatant kind of irrationality involves manifesting bad dispositions, thereby flouting some component of normative competence. A security worker who fails to take action upon observing a real-looking fake bomb manifests bad dispositions, for whatever dispositions are at play will indiscriminately manifest as failure to act across a range of cases involving real bombs. Similarly, a subject who believes that she ought to do A, but who fails to intend to do A, manifests bad dispositions, even if it is false that she ought to do A, for mere beliefs look from the inside like real reasons; it is simply not feasible to be disposed to only take into account real reasons.

Let me now turn to how the competence-based account can be extended to explain what is wrong with subjects who are means-ends incoherent.

\subsection{Means-ends incoherence}

Recall Ulla, who intends to run an ultramarathon in November, despite lacking good reasons to do so. Nevertheless, given that Ulla believes that it is necessary for her to train in order to run the marathon, she appears irrational if she has no intention whatsoever to integrate runs into her routine. At the very outset, however, I want to flag some problems for common characterizations of means-ends incoherence, for I think they are symptomatic. After putting forth my positive account, I will say why it is better suited to deal with these problems than ones positing requirements of structural rationality.

The following should sound familiar:

$s$ is means-ends incoherent just in case $s$ intends to do some action A, $s$ believes that doing $\mathrm{B}$ is a necessary means for doing $\mathrm{A}$, but $s$ does not intend to do B. 
There are a range of cases, however, in which a subject is means-ends incoherent in this way, but nothing seems amiss. Some means are automatic: I know that flexing my biceps is a necessary means for picking up the glass I am holding, but even if I intend to pick up my glass, I don't need to intend to flex my biceps. ${ }^{48}$ In some cases, necessary means are actions I can trust myself to perform, whether or not I now so intend. ${ }^{49}$ Note that these problems also threaten standard formulations of enkratic principles prohibiting akrasia. For instance, I believe that I ought to flex certain muscles (since I ought to open the door). But flexing my muscles is automatic; I don't need to intend to do so.

A widely endorsed response to such worries is to opt for a different characterization of means-ends incoherence:

$s$ is means-ends incoherent just in case $s$ intends to do some action A, believes that now intending to do B is a necessary means for doing A, but $s$ does not (now) intend to do $\mathrm{B}^{50}$

But consider just how restricted this principle is. I very much doubt that even intellectually sophisticated adults competent with the notion of an intention often hold beliefs about specific intentions being necessary means for doing various things. Consider a subject who intends to make it to the meeting in time, and who believes that leaving now is necessary for doing so, but who doesn't hold any such belief about the necessity of intending to leave now. At the very least, being in this combination of states is surely possible. If the subject forms no intention to leave, she nevertheless seems irrational.

In sum: while failing to intend a believed necessary often appears irrational, this is not always the case. An adequate account should be able to explain this, and to distinguish between cases in a principled way.

My general strategy has been to explain the seeming badness of various kinds of incoherence by appeal to the idea that incoherent subjects manifest bad dispositions, dispositions that are incompatible with some component of normative competence, and that, moreover, manifest in some cases as blatantly bad-seeming normative failures. The same is true, I will argue, of means-ends incoherent subjects, though the details will be a bit different. I will appeal to dispositions to track (or fail to track) an important structural feature of normative reality, the transmission of oughts to necessary means:

\section{Transmission}

If one ought to do $A$, and doing $B$ is a necessary means for doing $A$, then one ought to do B. ${ }^{51}$

\footnotetext{
${ }^{48}$ Cf. Harman (1986: 110-11).

${ }^{49}$ Cf. Setiya (2007: 668).

${ }^{50}$ For a sample of authors who formulate the requirement of means-ends coherence along these lines, see e.g. Harman (1976), Wallace (2001), Setiya (2007) Bratman (2009) and Lord (2019: 19). Broome (2013: 25) suggests restricting the enkratic requirement prohibiting akrasia to cases in which a subject not only believes that she ought to do A, but also believes that her doing A is controlled by her intentions.

${ }^{51}$ For some recent accounts relying on this principle, see Setiya (2007), Street (2008), Schroeder (2009) and Kiesewetter $(2015,2018)$. I will assume that the same notion of a necessary means is at play in both (putative) requirements of means-ends coherence and Transmission. It is clear that the necessity at issue is not metaphysical or even nomological. While I don't want to belittle the challenge of saying what sort of modality is at issue - an issue surprisingly rarely systematically addressed in the literature - we are routinely engaged in talk involving such weaker kinds of modality.
} 
I will assume that what is at issue here is what one all-things-considered ought to do. ${ }^{52}$ Unlike a requirement of means-ends coherence or instrumental rationality, Transmission doesn't make reference to an agent's intentions or beliefs. It says that oughts transmit to what are in fact necessary means, irrespective of the intentions or beliefs of an agent.

I cannot here offer a defense of Transmission. Along with many others, I find it intuitively compelling. ${ }^{53}$ And I find the counterexamples to the principle unconvincing. ${ }^{54}$ My conclusion here may be read as conditional: if Transmission is true, then we can give an account of what is wrong with means-ends incoherence. The idea will be that a core part of normative competence consists in being disposed to track this transmission of oughts, which I will argue typically involves extending one's intentions to believed necessary means.

If Transmission is true, then some facts about what one ought to do are true because doing these things is a necessary means for doing other things that one ought to do. Call these the transmitted facts, and those not true in virtue of the transmission of oughts the source facts. Normative competence involves being disposed to track both the source and transmitted facts. It is plausible that these in turn will involve different sub-competences: first, a (complex set of) dispositions allowing one to be moved to act in accordance with the true source facts, and second, a more structural kind of competence consisting of dispositions to extend one's motivations in a specific way. This more structural competence will play a key role in my account: I will argue that paradigmatically means-ends incoherent subjects fail to exercise this structural competence. Moreover, extending one's motivations in the way to be specified seems like the easy part of tracking facts about what one ought to do. Sometimes having the right ends is difficult, as is knowing what is a necessary means for what, but when one does have the right ends and knows what the necessary means to one's ends are, failing to pursue these necessary means seems like a particularly bad kind of normative failure.

Assume that I intend to do A, as I ought, and since doing B is necessary for doing A, by Transmission I also ought to do B. Consider how we paradigmatically manage to act in accordance with such transmitted ought-facts. At least very often (though not always ${ }^{55}$ ) doing something requires being in a prior motivational state directed at doing that very thing - in particular, I must get from an intention to do A to an intention to do B. Moreover, this will normally require knowing (and hence, believing) that doing $\mathrm{B}$ is necessary for doing A. But given points made above about the nature of belief, it is not feasible to be disposed in ways that discriminate between cases

\footnotetext{
${ }^{52}$ Cf. Setiya (2007). Kiesewetter (2015: 923) takes the relevant 'ought' to be one that settles practical deliberation concerning what one, all things considered, has reason to do.

${ }^{53}$ Kiesewetter (2015). Setiya (2007) and Schroeder (2009), for instance, rely on the principle without seeing any need to defend it.

${ }^{54}$ The most well-known counterexample to Transmission relies on cases like Jackson and Pargetter's (1986) case of Prof. Procrastinate. Procrastinate is invited to review a book. He has ample reasons to review it. In order to review it, it is necessary for him to accept the invitation. However, even if Procrastinate accepts the invitation, he is highly unlikely to write the review and we can assume that he knows this. So, the thought goes, he ought to review the book, but he ought not to accept the invitation. Given that accepting the invitation is a necessary means for reviewing the book, Transmission fails. I disagree with Jackson and Pargetter's treatment of this case: I think Procrastinate ought to review the book, and he ought to accept the invitation (and then go on to write the review). Kiesewetter (2015) argues that the most important challenges to Transmission are all based on the same idea.

${ }^{55}$ For reasons pointed out above, not always. The fact that we often track the transmission of oughts in a rather automatic way will be important for meeting the explanatory challenge raised in the beginning of this section.
} 
depending on whether something constitutes a real reason or a mere belief. For instance, it is not feasible to be disposed in ways that discriminate between mere beliefs and knowledge: one cannot be disposed to extend one's motivations to real necessary means, but not to mere believed necessary means.

Hence, a disposition to extend one's motivations from ends to necessary means will involve a disposition to extend one's motivations to believed necessary means. Being thus disposed, I want to suggest, is precisely the structural sub-competence enabling one to track the transmission of oughts to necessary means. The transmission of oughts is a structural feature of normative reality, and mirroring it is a structural competence, a disposition for one's motivations (or dispositions to act) to transmit from ends to believed necessary means. It involves responding to certain features of one's mental states - specific belief-intention pairs - by coming to be disposed to pursue the believed necessary means to one's ends. And at least in many cases, we come to be thus disposed by forming a new intention.

Consider again Ulla, who intends to run an ultra-marathon in November, believes that some serious training is necessary for doing so, but who forms no intention to start training. Recall that Ulla in fact ought not to run an ultra-marathon. But I have argued that a competence to track the transmission of oughts must involve a structural sub-competence, one that manifests as coming to be disposed to pursue believed necessary means to one's ends. Whatever dispositions Ulla is manifesting, it is clear that they are out of line with such a sub-competence. Having the right ends is not that easy, but at least in many cases, thus extending one's motivations seems like the easy part of tracking the transmission of oughts.

It is worth returning here to the local nature of the seeming badness of structural irrationality. My claim is not that every subject would be normatively better off across relevant, somewhat normal cases if they manifested the structural competence I have outlined. The local nature of the evaluations we are after is explained, I am arguing, by looking at components of normative competence - roughly, dispositions that, together with other feasible dispositions, tend to manifest as normative success (doing, intending, believing, etc., as one ought). Consider again what it takes to be a good lifeguard. This will involve various sub-competences, manifesting as component successes: for instance, one must be able to recognize alarming situations (e.g. the signs of drowning), and to make the right interventions, which result in getting the person identified as being in distress out of the water. If someone is very bad at recognizing alarming situations, their complete incompetence at even getting to the people they have identified as needing help might in fact prevent them from making mistakes like dragging someone happily swimming out of the ocean. Despite this, they manifest incompetence, and are criticizable for doing so.

Similarly, consider the success of acting as one ought. Someone who systematically fails to track the source ought-facts, being motivated to do things they ought not to do, might overall be better off if she also flouted the structural sub-competence, for her systematic inability to pursue necessary means to her ends would then fend off normative failure. Still, if I am right that a competence to track transmitted ought-facts requires a disposition for one's motivations to transmit to believed necessary means, she is still manifesting normative incompetence. Moreover this part of normative competence seems less demanding than, for instance, that involved in having ends corresponding to the true source-facts. Other things being equal, for instance, we would expect subjects to be able to extend their motivations to believed necessary means. Indeed, when one's normative failure is due to such failure to extend one's motivations, it seems particularly blatant: if I intend to do A, as I ought, and I know that doing B is necessary for doing A, then other things being equal, it seems particularly bad for me to fail to intend to do B. 
An account of what is wrong with means-ends incoherent subjects along these lines has several virtues. Unlike most other accounts that don't simply invoke a requirement of means-ends coherence, my account doesn't rely on any particular view of intention. Neither does it rely on an implausible luminosity assumption to the effect that means-ends incoherent subjects are always in a position to know that they are means-ends incoherent. ${ }^{56}$ Further, recall the kinds of problems encountered when trying to formulate a requirement of means-ends coherence: a familiar first pass requirement has counterexamples, but a popular fix only applies in a narrow range of cases. A merit of the account proposed is that it can explain why failing to intend believed necessary means seems blatantly irrational in some cases, but not in others. The structural aspect of a competence to track facts about transmission requires that one's dispositions to act spill over from ends to believed necessary means. In paradigm cases, this involves the spilling over of intentions from ends to believed necessary means. But not always: I don't need to intend to flex my muscles in order to do so. I become disposed to flex my muscles (in order to get up) just by forming an intention to open the door. Similarly, in cases in which I rightly trust myself to do certain things, I am disposed to do those things even if I don't now intend to do them.

Before concluding my discussion of means-ends incoherence, let me address an objection to the account I have sketched. ${ }^{57}$ Consider so-called "permissive cases": cases in which a subject is permitted, but not required, to do A. Assume that a subject in such a case intends to do A, and believes that doing B is a necessary means for doing A, but nevertheless fails to intend to do A. The worry is that my account cannot explain why such a subject is criticizable. In particular, we could imagine a subject who is disposed to track the transmissions of oughts, and whose means-ends incoherence tends to be restricted to such permissive cases. Even if permissions transmitted to necessary means, not doing (or intending to do) something one is merely permitted to do is not a normative failure.

Given widely accepted views about reasons, such "permissive cases" will have the following structure. ${ }^{58}$ First, in order for one to be permitted to do A, there must be an undefeated reason to do A. However, one is merely permitted (and not required) to do A because one also has an undefeated reason to do B, and one cannot do both. (For instance, perhaps I have equally good reasons to cook lentil soup and pasta for dinner, but because of time constraints, I cannot do both.) In such a case, one is permitted to intend to do A, and one is permitted to intend to do B. However, I think it is plausible that in such a case resolving the standoff by forming an intention makes a normative difference: if I form the intention to cook lentil soup instead of pasta for dinner, my overall balance of reasons now weights in favor of lentil soup. Here is one explanation why. ${ }^{59}$ I ought, after all, do either A or B (assuming those are the only options). And in order for me to do either A or B and not end up like Buridan's ass, I must commit to one and then, having made a choice, carry through with it. It is necessary for me to either choose to do A or choose to do B, and to carry through with whichever choice I make. The fact that I ought to do one of the things I am permitted to do, then,

\footnotetext{
${ }^{56}$ E.g. Kolodny (2007a).

${ }^{57}$ Many thanks to Alex Worsnip for raising this worry.

${ }^{58}$ Widely accepted, but not wholly uncontroversial. For a criticism - and the view that normative reasons have two separable dimensions of strength, a justifying strength and a requiring strength - see Gert (2003). I am setting aside cases involving incommensurable reasons/values (some might view those, too, as permissive cases).

${ }^{59}$ Alternatively, one could argue, along the lines of Chang (2013), that commitments give rise to reasons, supplemented with the idea that intentions give rise to commitments. But Chang (2013) argues against the idea that commitments are decisions, intentions, or plans - instead, she argues, they are what she calls willings.
} 
together with an application of Oughts Transmission, explains why, in such permissive cases, forming an intention one way or another makes a normative difference. ${ }^{60}$ If this is right, then if I am in the sort of permissive case described, and I permissibly intend to do A, then I in fact ought to do A: my forming an intention one way rather than the other breaks the balance of reasons. If this is right, and I intend something I am permitted to do, then we can once again apply Oughts Transmission: I ought to pursue the necessary means to cooking lentil soup.

Before concluding, let me make some final remarks. The kind of evaluative perspective I have deployed to explain the seeming badness of paradigm cases of incoherence is focused on the dispositions manifested by incoherent agents: these dispositions, I have argued, are at odds with normative competence, and manifest in other cases that one cannot feasibly discriminate from one's actual case as blatant-seeming normative failures. Various authors have tried to explain the seeming normativity of structural requirements of rationality by using the language of dispositions. A common theme has been the idea that being structurally rational is a means of doing what one has reason to do. ${ }^{61}$ However, at least given a natural way of construing talk of instrumental means, on my view a disposition to conform to structural requirements is not merely an instrumental, contingent means to believing and doing what one has reason to believe and do. What makes a disposition good or bad in the relevant sense is not whether its manifestations are means to success, but whether its manifestations tend to constitute successes. Getting enough sleep might be an instrumentally good disposition for an airport security worker to have, for being alert is instrumental to successfully recognizing bombs. By contrast, dispositions constituting recognitional capacities and competences are related to success in a more direct way: manifesting them isn't merely an instrumental means to success; in good cases, manifesting them constitutes successes like recognizing real bombs.

One objection often raised for views that regard rationality as a kind of virtue is that they cannot account for the normative (as opposed to merely evaluative) dimension of the distinct charge of irrationality. Kolodny (2005: 554-5) argues that this normative dimension is manifest both 'from the outside', in the form of advice about what one ought to do or believe, and 'from the inside', as pressure to be in states that rationality requires of us. But I claim that we often do make normative-sounding evaluations from a perspective oriented around good dispositions. Recall Simu, the candidate lifeguard who fails to act despite witnessing a simulation of a classic drowning response. It would feel perfectly appropriate for bystanders aware of the virtual-reality test to say, "He should jump in!". It is this same evaluative perspective centered around dispositions and competences that explains our normative indignation at paradigmatically incoherent subjects.

\section{Conclusions}

In the first half of this paper I motivated my positive project, which is explaining the distinct kind of normative disapproval invited by paradigm cases of incoherence

\footnotetext{
${ }^{60}$ Note that my claim is not that an intention to do A always, as such, counts as a reason to do A - I agree that we cannot "bootstrap" a reason to do A into existence just by intending to do A (see Bratman (1987) for the bootstrapping objection). See also Broome (2001) for why intentions don't as such provide reasons.

${ }^{61}$ Kolodny (2008a: 442) expresses the idea, which he attributes in some form to both John Broome and Michael Bratman, as follows: "by being disposed to satisfy requirements of formal coherence over the long run, one takes means to believing or choosing what reason requires over the long run." See also Bratman (1987: 35), Broome (2005) and Raz (2005).
} 
without appealing to special requirements of structural rationality. I argued that such requirements offer a poor explanation and vindication of our evaluative practices and inclinations.

In the second part of this paper I sketched a positive account of the distinct-seeming charge of irrationality elicited by paradigmatically incoherent subjects. On my view, there are no requirements of structural rationality. Rather, there are substantive requirements stating what one ought to do, intend, and believe, and then there are good dispositions that tend to manifest as norm-conforming actions, intentions, and beliefs - dispositions that constitute normative competence. We often occupy an evaluative perspective focused on dispositions and competences, and the normative language of should and oughts comes naturally with it. A wide range of paradigmatic cases of incoherence, I have argued, involve manifesting problematic dispositions, dispositions that manifest across a range of cases as blatant-seeming normative failures.

I have explained a distinct-seeming charge of irrationality by appeal to our sense that certain normative failures are worse than others, and, relatedly, that failure to exercise certain components of competence is particularly bad. Given that we are trying to explain the distinct-seeming disapproval that comes with a charge of a blatant kind of irrationality, I think it is fair game to appeal to our sense that certain normative failures - certain cases of failing to conform to substantive normative requirements - strike us as more blatant than others. As we have seen, our evaluative inclinations are sensitive to a complex array of background details. If there isn't any natural way of delineating the blatant failures from others that is independent of our inclinations as evaluators, that is more or less what we should expect. ${ }^{62}$

\section{References}

Bratman M.E. (1987). Intention, Plans and Practical Reason. Cambridge, MA: Harvard University Press.

Bratman M.E. (2009). 'Intention, Belief, Practical, Theoretical.' In J. Timmerman, J. Skorupski and S. Robertson (eds), Spheres of Reason, pp. 29-62. Oxford: Oxford University Press.

Broome J. (2001). 'Are Intentions Reasons? And How Should We Cope with Incommensurable Values?' In C. Morris and A. Ripstein (eds), Practical Rationality and Preference: Essays for David Gauthier, pp. 98120. Cambridge: Cambridge University Press.

Broome J. (2005). 'Does Rationality Give Us Reasons?' Philosophical Issues 15, 321-37.

Broome J. (2013). Rationality Through Reasoning. Oxford: Wiley Blackwell.

Chang R. (2013). 'Commitment, Reasons, and the Will.' In R. Shafer-Landau (ed.), Oxford Studies in Metaethics: Volume 8, pp. 74-113. Oxford: Oxford University Press.

Feldman R. (2005). 'Respecting the Evidence.' Philosophical Perspectives 19, 95-119.

Gert J. (2003). 'Requiring and Justifying: Two Dimensions of Normative Strength.' Erkenntnis 59, 5-36.

Greenspan P. (1975). 'Conditional Oughts and Hypothetical Imperatives.' Journal of Philosophy 72, 259$76,265$.

Harman G. (1976). 'Practical Reasoning.' Review of Metaphysics 29, 431-63.

Harman G. (1986). Change in View: Principles in Reasoning. Cambridge, MA: MIT Press.

Horowitz S. (2014). 'Epistemic Akrasia.' Noûs 48(4), 718-44.

Huemer M. (2011). 'The Puzzle of Metacoherence.' Philosophy and Phenomenological Research 82, 1-21.

\footnotetext{
${ }^{62}$ Many thanks to an audience at Fordham University and the University of Helsinki, and Giada Frantantonio, Jaakko Hirvelä, Diana Heney, Lilian O’Brien, Mika Oksanen, Niall Paterson, Paul Silva, Kurt Sylvan, and Ninni Suni. Special thanks to Asbjørn Steglich-Petersen, Alex Worsnip, and Daniel Drucker for extensive written comments on an earlier draft. Many thanks to Benjamin Kiesewetter for comments that I was not able to fully incorporate, but that will influence my future work on the topic. This project has received funding from the European Research Council (ERC) under the European Union's Horizon 2020 research and innovation programme under grant agreement No. 758539.
} 
Jackson F. and Pargetter R. (1986). 'Oughts, Options and Actualism.' Philosophical Review 95, 233-55.

Johnson King Z.A. (2019). 'We Can Have Our Buck and Pass It, Too.' In R. Schafer-Landau (ed.), Oxford Studies in Metaethics, vol. 14. Oxford: Oxford University Press.

Kant I. (1997). Groundwork of the Metaphysics of Morals, trans. M. Gregor. Cambridge: Cambridge University Press.

Kauppinen A. (2021). 'Rationality as the Rule of Reason.' Noûs 55(1), 538-59.

Kiesewetter B. (2015). 'Instrumental Normativity: In Defense of the Transmission Principle.' Ethics 125, 921-46.

Kiesewetter B. (2018). 'Contrary-to-Duty Scenarios, Deontic Dilemmas, and Transmission Principles.' Ethics 129, 98-115.

Kolodny N. (2005). 'Why be Rational?' Mind 114, 509-63.

Kolodny N. (2007a). 'How Does Coherence Matter?” Proceedings of the Aristotelian Society 107, $229-63$.

Kolodny N. (2007b). 'State or Process requirements?" Mind 116, 371-85.

Kolodny N. (2008a). 'Why be Disposed to be Coherent?' Ethics 118, 437-63.

Kolodny N. (2008b). 'The Myth of Practical Consistency.' European Journal of Philosophy 16, 366-402.

Korsgaard C. (1996). Sources of Normativity. Cambridge: Cambridge University Press.

Lasonen-Aarnio M. (2010). 'Unreasonable Knowledge.' Philosophical Perspectives 24, 1-21.

Lasonen-Aarnio M. (2015). 'New Rational Reflection and Internalism about Rationality.' Oxford Studies in Epistemology 5, 145-79.

Lasonen-Aarnio M. (2020). 'Enkrasia or Evidentialism? Learning to Love Mismatch.' Philosophical Studies 177, 597-632.

Lasonen-Aarnio M. (2021). 'Dispositional Evaluations and Defeat.' In J. Brown and M. Simion (eds), Reasons, Justification and Defeat. Oxford: Oxford University Press.

Lasonen-Aarnio M. (Forthcoming a). 'Competent Failure and Victims of Deceit.' In J. Dutant and F. Dorsch (eds), The New Evil Demon. Oxford: Oxford University Press.

Lasonen-Aarnio M. (Forthcoming b). 'Perspectives and Good Dispositions.' Philosophy and Phenomenological Research.

Littlejohn C. (2018a). 'Stop Making Sense? On a Puzzle About Rationality.' Philosophy and Phenomenological Research 96(2), 257-72.

Littlejohn C. (2018b). 'Reasons and Theoretical Rationality.' In D. Star (ed.), Oxford Handbook of Reasons and Normativity, pp. 529-52. Oxford: Oxford University Press.

Lord E. (2019). The Importance of Being Rational. Oxford: Oxford University Press.

Raz J. (2005). 'The Myth of Instrumental Rationality.' Journal of Ethics and Social Philosophy 1, 1-28.

Rinard S. (2018). 'Believing for Practical Reasons.' Nô̂s 53, 763-84.

Rinard S. (2019). 'Equal Treatment for Belief.' Philosophical Studies 176, 1923-50.

Ross J. and Schroeder M. (2014). 'Belief, Credence, and Pragmatic Encroachment.' Philosophy and Phenomenological Research 88, 259-88.

Scanlon T. (1998). What We Owe to Each Other. Cambridge, MA: Harvard University Press.

Schroeder M. (2009). 'Means-End Coherence, Stringency, and Subjective Reasons.' Philosophical Studies $143,223-48$.

Setiya K. (2004). 'Against Internalism.' Noûs 38, 266-98.

Setiya K. (2007). 'Cognitivism About Instrumental Reason.’ Ethics 117, 649-73.

Smithies D. (2012). 'Moore's Paradox and the Accessibility of Justification.' Philosophy and Phenomenological Research 85, 273-300.

Sylvan K. (2016). 'Epistemic Reasons I: Normativity.' Philosophy Compass 11, 364-76.

Street S. (2008). 'Constructivism about Reasons.' Oxford Studies in Metaethics 3, 207-45.

Titelbaum M.G. (2015). 'Rationality's Fixed Point (Or: In Defence of Right Reason).' Oxford Studies in Epistemology 5, 253-94.

Velleman D. (1989). Practical Reflection. Princeton, NJ: Princeton University Press.

Velleman D. (2000). The Possibility of Practical Reason. Oxford: Oxford University Press.

Way J. (2018). 'Reasons and Rationality.' In D. Star (ed.), The Oxford Handbook of Reasons and Normativity, pp. 485-503. Oxford: Oxford University Press.

Wallace J. (2001). 'Normativity, Commitment, and Instrumental Reason.' Philosophers' Imprint 1, 1-26.

Williamson T. (2000). Knowledge and Its Limits. Oxford: Oxford University Press.

Williamson T. (2014). 'Very Improbable Knowing.' Synthese 79, 971-99. 
Williamson T. (2017). 'Acting on Knowledge.' In J.A. Carter, E. Gordon and B. Jarvis (eds), Knowledge-First, pp. 163-81. Oxford: Oxford University Press.

Worsnip A. (2018). 'The Conflict of Evidence and Coherence.' Philosophy and Phenomenological Research 96, 3-44.

Maria Lasonen-Aarnio is Professor of Theoretical Philosophy at the University of Helsinki. She is the Principal Investigator in the European Research Council Project Competence and Success in Epistemology and Beyond.

Cite this article: Lasonen-Aarnio M (2021). Coherence as Competence. Episteme 18, 453-476. https:// doi.org/10.1017/epi.2021.33 